\title{
ПРОЕКТИРОВАНИЕ И ИЗГОТОВЛЕНИЕ ДОПОЛНИТЕЛЬНОГО ОБОРУДОВАНИЯ ДЛЯ ПОДГОТОВКИ ЛЕДОВЫХ И СНЕГОВЫХ ТРЕКОВ ИСПЫТАТЕЛЬНОГО ПОЛИГОНА СВФУ
}

\author{
Игнатьев Андрей Дмитриевич \\ заведующий учебно-производственной базой \\ Бехзад Абдуллах \\ Пулотов Мухаммаджон Рашиджонович \\ студенты \\ Научный руководитель: Ноев Иван Иванович \\ к.т.н., доцент \\ ФГАОУ ВО «Северо-Восточный федеральный \\ университет имени М.К. Аммосова»
}

\begin{abstract}
Аннотация: в данной статье приведены результаты проектирования, изготовления и применения дополнительных оборудований: универсальный отвал, снегоуборочный отвал. Разработанный проект внедрен и позволяет повышать уровень качества подготовки и содержания снеговых и ледовых треков Испытательного полигона.
\end{abstract}

Ключевые слова: универсальный отвал, снегоуборочный отвал, снеговые треки, полигон, зимние испытания.

\section{DESIGN AND MANUFACTURE OF ADDITIONAL EQUIPMENT FOR THE PREPARATION OF ICE AND SNOW TRACKS OF THE NEFU TEST SITE}

\section{Ignatyev Andrey Dmitrievich Behzad Abdullah Pulatov Mukhammadjon Rashidkhonovich Scientific adviser: Noev Ivan Ivanovich}

\footnotetext{
Abstract: this article presents the results of the design and manufacture of additional equipment: universal blade, snow removal blade. The developed project has been implemented and makes it possible to improve the quality of preparation and maintenance of snow and ice tracks of the Test Site.
} 
Keywords: universal blade, snow removal blade, snow tracks, landfill, winter tests.

Автомобилестроение является одним из наиболее сложных и наукоемких сегментов машиностроения. Внутренняя и внешняя конкуренция в данной отрасли предъявляет высочайшие требования по надежности автомобильных компонентов, узлов и агрегатов в жестких условиях эксплуатации.

В Северо-Восточном федеральном университете имени М. К. Аммосова на базе Автодорожном факультета в 2017 году создано ООО «Испытательный полигон СВФУ». Цель проекта: строительство испытательного полигона автомобильных шин в зимний период времени на территории опережающего социально-экономического развития «Индустриальный парк «Кангалассы». Главной целью проекта является реализация ключевых преимуществ региона и его социально-экономическое развитие за счет использования природного и человеческого потенциала территории, уникальных климатических условий путем строительства и эксплуатации испытательного полигона.

Достоинством универсального испытательного полигона для различных типов тестовых испытаний и экспериментального сопровождения в условиях низких температур является то, что в нем органически соединились характерные особенности как лабораторных, так и эксплуатационных испытаний. С одной стороны, на испытательных треках для зимнего комплекса испытаний различной конфигурации, обеспечивающем равное сопротивление движению, при испытаниях представляется возможным задавать и поддерживать любые постоянные режимы работы транспортной техники. С точки зрения методики и организации опытов здесь гарантированы, по существу, лабораторные условия. С другой стороны, на Полигоне обеспечиваются реальные эксплуатационные условия взаимодействия транспортной техники с внешней средой в условиях сложных климатических условиях Севера, также поддерживается внедрение инновационных технологий, могут будут способствовать повышению уровня безопасности на дорогах.

Настоящая научно-исследовательская и опытно-конструкторская работа «Техника и технологии для подготовки ледовых и снеговых треков Испытательного полигона СВФУ в целях проведения испытаний автомобильных шин и автомобилей в условиях криолитозоны и экстремально низких температур» реализуется во исполнение Договоров на оказание услуг по проведению испытаний между Корпорацией «Бриджстоун», АО «АВТОВАЗ», 
ШИЦ «Вершина»; плана мероприятий (Дорожной карты) по реализации проекта строительства Испытательного полигона автомобильных шин в ТОР «Якутия» на 2017-2020 годы, утвержденного 11.05.2017 г. Главой Окружной администрации г. Якутска, ректором СВФУ и генеральным директором ООО «Индустриальный парк «Кангалассы» в соответствии с меморандумом о намерениях между Корпорацией «Бриджстоун» и Северо-Восточным федеральным университетом №95-11/15-с от 17.11.2015 г.

Целью НИОКР является повышение качества подготовки и содержания снеговых и ледовых треков Испытательного полигона СВФУ.

Основные задачи НИОКР:

1. Разработка проектных решений дополнительного оборудования.

2. Изготовление опытно-промышленных образцов дополнительного навесного и прицепного оборудования.

3. Опытно-экспериментальная апробация образцов дополнительного оборудования.

Для обслуживания и содержания снеговых и ледовых треков требуется спецтехника и оборудование, предназначенное для выравнивания утрамбованного снегового полотна трека, уборки снега и проведения испытаний автомобильных шин и автомобилей в условиях естественно низких температур.

Опытный образец отвала спроектирован к действующей на полигоне тракторе «Беларус 320» и погрузчика «Volvo MC95C».

На трактор «Беларус 320» создан универсальный отвал со спецификацией: ширина - не более 230 см.; высота - не менее 60 см.; толщина - не менее 3 мм.; нож резиновый - не менее 10 см.; нож металлический - не менее 7 см.; рекомендуемая марка стали $08 Ю-4$ мм.

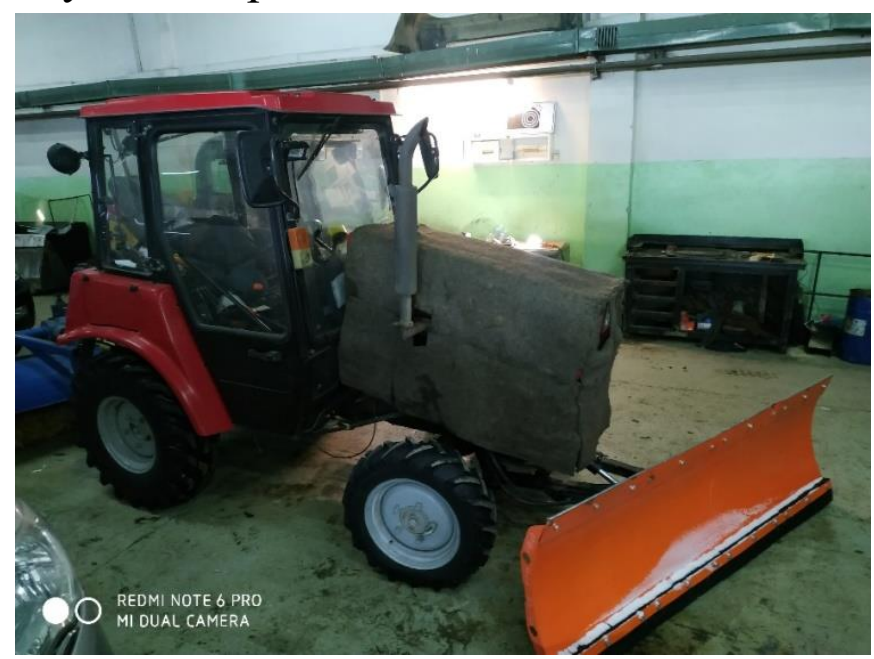

Рис. 1. Универсальный отвал 
Для фронтального погрузчика «Volvo MC95C» создан снегоуборочный отвал со спецификацией: ширина - не менее 2500 мм.; высота - не более 1000 мм.; угол поворота - не более $+15 /-15^{\circ}$.

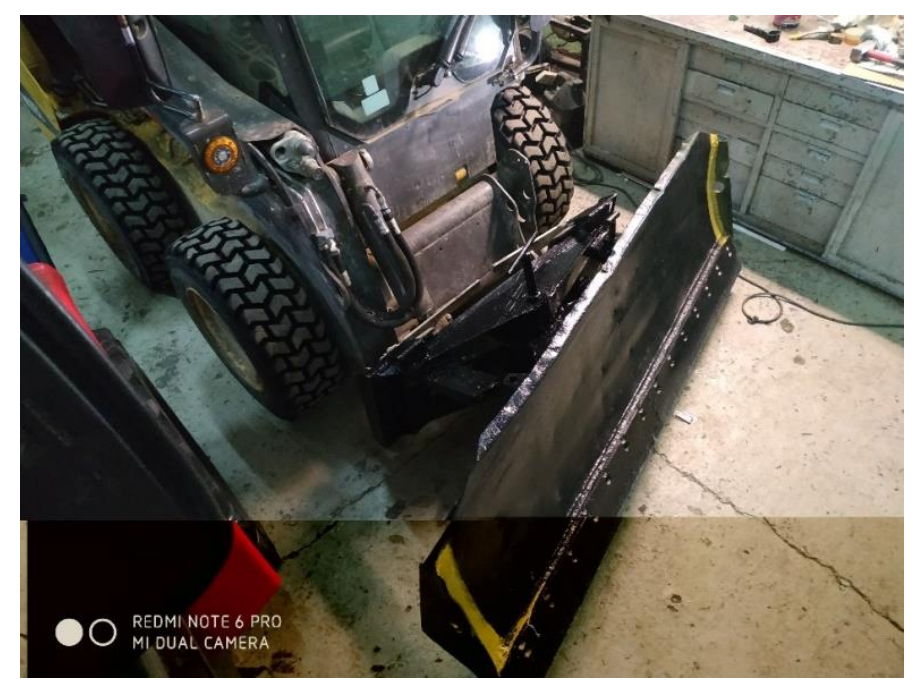

Рис. 2. Снегоуборочный отвал

Особенность универсального отвала к трактору является совмещение переворотной лопаты с двумя рабочими поверхностями:

1. Сторона, оборудованная армированной резиной.

2. Сторона со съёмными металлическими ножами.

Сторона универсального отвала, оборудованная армированной резиной, применяется для выравнивания и уборки свежевыпавшего снега на снеговых и ледовых треках. Упругий резиновый нож выравнивает неровности после прохождения катка снегоуплотнителя. Вместе с тем, резина, армированная стальным тросом, не трескается при самых сильных якутских морозах, является ударостойким.

Сторона универсального отвала со съёмным металлическим ножом осуществляет лёгкие планировочные работы: уборка наледи, работа на грунтах I-II категории (песок, суглинок лёгкий влажный, гравий мелкий и средний, глина лёгкая влажная).

Снегоуборочный отвал к фронтальному погрузчику практически не отличается от универсального отвала к трактору: та же лопата, тот же механизм поворота. Конструктивное отличие - навесная рама, с помощью которой отвал крепится к погрузчику. Рама выполнена из квадратной трубы 80х80мм, что обеспечивает прочность и долговечность данной конструкции.

Преимущества разработанных снегоуборочных отвалов:

- наличие прочного механизма, поддерживающего заданный градус угла поворота ножа; 
- возможность поперечного движения вдоль рамы в диапазоне \pm 5 градусов;

- имеющаяся функция плавания в диапазоне около 40 мм позволяет отрегулировать отвал в зависимости от убираемой площади;

- встроенная пружина, защищающая всю конструкцию от чрезмерного давления снега.

Реализованный НИОКР имеет важное значение для привлечения студентов в научно-исследовательскую и конструкторскую деятельность.

Разработанный проект внедрен и позволяет повышать уровень качества подготовки и содержания снеговых и ледовых треков Испытательного полигона.

\section{Список литературы}

1. ASTM F1805-06. Historical Standard. Стандартный метод испытания для измерения силы сцепления колеса, едущего по прямой линии на покрытых снегом и льдом поверхностях.

2. ГОСТ 16504-81. Система государственных испытаний продукции. Испытания и контроль качества продукции. Основные термины и определения (с изм. № 1, октябрь, 2003 г.).

3. Филиппов Д. В., Ноев И. И. Инновационные решения в проведении тестовых испытаний и экспериментального сопровождения в условиях низких температур на базе универсального испытательного полигона СВФУ // Устойчивый Север: общество, экономика, экология, политика: сборник трудов $\mathrm{V}$ всероссийской научно-практической конференция (г. Якутск, 24-26 сентября 2019 г.). - Уфа, 2019. - Ч. 1. - С. 286-293.

(С) И.И. Ноев, А.Д. Игнатьев, А. Безхад, М.Р. Пулотов, 2022 